\title{
Dry period and parturient predictors of early lactation hyperketonemia in dairy cattle
}

\author{
J. A. A. McArt, ${ }^{*}$ D. V. Nydam, ${ }^{* 1}$ and G. R. Oetzel† \\ *Department of Population Medicine and Diagnostic Sciences, College of Veterinary Medicine, Cornell University, Ithaca, NY 14853 \\ †School of Veterinary Medicine, University of Wisconsin, Madison 53706
}

\begin{abstract}
The purpose was to determine important dry and calving period predictors of (1) a cow developing hyperketonemia at any time between 3 and $16 \mathrm{~d}$ in milk (DIM) and (2) a cow having hyperketonemia at her first $\beta$-hydroxybutyrate (BHBA) test after calving (between 3 and 5 DIM). Cows from 4 freestall dairy herds [2 in New York (NY) and 2 in Wisconsin] were enrolled at 266 d carried calf. Precalving data included body condition score, locomotion score, and blood nonesterified fatty acids (NEFA) concentration; calving-associated data included previous days carried calf, calving ease, calf sex, twins, stillbirth, and parity. Cows were each tested 6 times for hyperketonemia from 3 to 16 DIM on Mondays, Wednesdays, and Fridays using the Precision Xtra meter (Abbott Laboratories, Abbott Park, IL). Hyperketonemia was defined as a blood BHBA concentration of $\geq 1.2 \mathrm{mmol} / \mathrm{L}$. Multivariable fixed-effects Poisson regression models were developed to predict the probability of a cow developing hyperketonemia between either 3 and 16 DIM or at her first BHBA test. As only the NY herds had precalving NEFA data, each prediction model was developed twice: once with data from all 4 herds $(\mathrm{n}=1,672)$ and once with data from only the NY herds $(\mathrm{n}=544)$. For the models with data from all 4 herds, increased body condition score group and an interaction between advanced parity and herd were important predictors of hyperketonemia development at any time from 3 to 16 DIM; calf sex (male), herd, and an advanced parity by increased body condition score group interaction were important predictors of hyperketonemia development between 3 and 5 DIM. The 4-herd models had a 64 and $78 \%$ predictive concordance for hyperketonemia between 3 and 16 DIM and at first BHBA test, respectively. For the models with data from the NY herds only, increased NEFA, calf sex (male), advanced parity, and herd were found to be important predictors of hyperketonemia development
\end{abstract}

Received May 2, 2012.

Accepted September 10, 2012.

${ }^{1}$ Corresponding author: dvn2@cornell.edu at any time from 3 to 16 DIM; increased NEFA, calf sex (male), decreased calving ease, stillbirth, and advanced parity were important predictors of having hyperketonemia at first BHBA test. The NY models had a 69 and $87 \%$ predictive concordance, respectively. These results may help identify at-risk animals and improve dry-cow management strategies before hyperketonemia develops.

Key words: dairy cow, hyperketonemia, nonesterified fatty acid, prediction

\section{INTRODUCTION}

All dairy cows transition through a state of negative energy balance during early lactation when the energy demands of milk production cannot be met by feed intake alone (Bauman and Currie, 1980; Baird, 1982; Herdt, 2000). Cows unable to adequately transition through this period often develop hyperketonemia, an excessive elevation of ketone bodies in the blood (Herdt, 2000). The negative effects of hyperketonemia on individual cow health and dairy economics are well reported. Hyperketonemic cows are more likely to develop displaced abomasa (LeBlanc et al., 2005; Duffield et al., 2009; Ospina et al., 2010a) and be culled than nonhyperketonemic cows (Gröhn et al., 1998; McArt et al., 2012). In addition, hyperketonemia has been found to result in a substantial loss in milk yield during early lactation (Dohoo and Martin, 1984; Duffield et al., 2009; Ospina et al., 2010b). Economic losses due to treatment costs, increased culling, and decreased milk production have been estimated at $\$ 211$ per case of clinical hyperketonemia (C. Guard, Cornell University, Ithaca, NY, personal communication, 2012) and $\$ 78$ per case of subclinical hyperketonemia (Geishauser et al., 2001). McLaren et al. (2006) found that an economic index of return over feed (milk income minus feed cost) in Ontario (Canada) dairy herds decreased by $\$ 0.015$ per cow per day for every $1 \%$ increase in the herd incidence of subclinical hyperketonemia.

Although the development of hyperketonemia is multifactorial, it has been suggested that body condition at calving and proper nutrition during the transition 
period can affect negative energy balance during early lactation and, thus, development of hyperketonemia. A review by Overton and Waldron (2004) concluded that cows with a moderately lower BCS that are well managed during the transition period are more likely to adequately transition into lactation than cows of higher BCS, possibly due to their ability to increase DMI in early lactation. Multiple studies have indicated that nutritional management during the dry period can affect postpartum health and production, and that overfeeding increases prepartum NEFA levels, decreases DMI before calving, and increases blood BHBA after calving (Dann et al., 2006; Douglas et al., 2006; Janovick et al., 2011).

The time of hyperketonemia development is an important prognostic indicator of downstream events. A recent observational study on large confinement dairies showed that the incidence of hyperketonemia, defined as a blood BHBA concentration of $\geq 1.2 \mathrm{mmol} / \mathrm{L}$, peaks at 5 DIM, with $75 \%$ of cows that ever develop hyperketonemia first testing positive between 3 and 7 DIM. Cows first testing positive between 3 to 7 DIM were more likely to develop a displaced abomasum or leave the herd in the first 30 DIM, less likely to conceive to first service, and produced less milk in the first 30 DIM than cows testing positive from 8 to 16 DIM (McArt et al., 2012).

These reasons underscore the importance of identification of factors during the transition period that may affect the development of hyperketonemia in early lactation. Knowledge of these factors may improve the ability to predict which cows will develop hyperketonemia, allowing preventative measures and more focused testing for certain groups of animals. The objectives of this study were to determine important dry and calving period risk factors of (1) a cow developing hyperketonemia at any time between 3 and 16 DIM and (2) a cow having hyperketonemia at her first BHBA test (between 3 and 5 DIM).

\section{MATERIALS AND METHODS}

\section{Study Population}

Data were collected from 2 dairy farms (farms A and B) in New York (NY) from May 18, 2010, to September 8, 2010, and from 2 dairy farms (farms C and D) in Wisconsin from June 11, 2010, to August 30, 2010. To be selected, farms had to meet the following criteria: milk at least 1,500 cows, have headlocks in fresh cow pens, use the farm management program Dairy Comp 305 (Valley Agricultural Software, Tulare, CA), and be willing to participate in the proposed data col- lection and hyperketonemia testing protocol. In-depth information concerning farm management structure, nutrition, and reproductive and disease events has been previously published (McArt et al., 2011).

\section{Data Collection and Study Design}

Precalving data was collected twice weekly on cows starting at approximately $266 \mathrm{~d}$ carried calf, and included BCS (Ferguson et al., 1994), locomotion score (LS; a modification of the system proposed by Nordlund et al., 2004), and blood collection for NEFA concentration (NY herds only). Body condition was assessed on a 5 -point scale with 0.25 -unit increments, with a higher score representing a greater body condition. Locomotion score was assessed on a 4-point scale with scores assigned from 1 to 4, representing non-lame, slightly lame, moderately lame, and severely lames cows, respectively. In the NY herds, blood was collected from the coccygeal vessels of each cow using a tube without anticoagulant and a 20-gauge $\times 2.54-\mathrm{cm}$ blood-collection needle. Samples were immediately placed on ice and serum separated in a centrifuge at 2,000 $\times g$ for 10 min within $1 \mathrm{~h}$ of collection. Serum samples were kept on ice until laboratory analysis (Stokol and Nydam, 2005). Body condition and lameness were scored by one individual in each region throughout the study. Additional postcalving data exported throughout the study period from each farm's Dairy Comp 305 program included previous days carried calf (PDCC), calving ease (CEASE; using a 1 to 5 scale, with 1 representing no assistance and 5 representing extreme assistance), calf sex (CSEX), twins, stillbirth, and parity.

To determine an outcome of hyperketonemia, cows were tested from 3 to 16 DIM on Mondays, Wednesdays, and Fridays for hyperketonemia using a Precision Xtra meter (Abbott Laboratories, Abbott Park, IL). The Precision Xtra meter is a hand-held device used to test blood BHBA concentrations; sensitivity and specificity compared with serum BHBA concentrations determined photometrically are 88 to $96 \%$ and 96 to $98 \%$, respectively, when using a cut-off value of $\geq 1.2$ mmol/L (Iwersen et al., 2009; Konkol et al., 2009). Given this testing scheme, each cow was sampled 6 times, beginning at 3,4 , or 5 DIM and ending on 14,15 , or 16 DIM. Hyperketonemia was defined as a BHBA concentration of $\geq 1.2 \mathrm{mmol} / \mathrm{L}$. All hyperketonemia testing of cows from 3 to 16 DIM was completed by the research team during the study.

Cows were excluded from the analysis if their PDCC was less than 260, if they died or were sold before their first BHBA test, or for lack of proper identification. Additionally, for the outcome concerning the develop- 
ment of hyperketonemia at any time between 3 and 16 DIM, cows remaining in the herd through 16 DIM were excluded if they had fewer than 5 BHBA tests. For the outcome concerning hyperketonemia at first BHBA test, cows without a recorded BHBA concentration at first test were excluded from the analysis.

A proposal was reviewed and approved by the Cornell University Institutional Animal Care and Use Committee (no. 2008-0099) and the University of WisconsinMadison School of Veterinary Medicine Animal Care and Use Committee (no. V01479-0-05-10). All farms were asked to sign a consent form agreeing to the proposed data collection and testing protocol.

\section{Statistical Analysis}

Two predictive models were developed: (1) hyperketonemia at any time between 3 and 16 DIM (HYPKTN), and (2) hyperketonemia at first BHBA test (HYPKTN1). Each predictive model was developed using 2 differing data sets: (1) data from all herds that excluded blood NEFA concentration from the NY herds or (2) data from the NY herds that included blood NEFA concentration. For the subjective measurements of BCS and LS, the weighted kappa values (a measure of agreement; Landis and Koch, 1977) between the raters were 0.19 (slight) and 0.49 (moderate), respectively. Given only a slight agreement between raters for BCS, a within-rater adjustment was performed. The BCS of cows by each rater was grouped into 3 categories $(1,2$, and 3$)$ based on cows with a BCS less than the median, the median score, or a BCS greater than the median, respectively. The weighted kappa value comparing BCS group (BCSG) between raters was 0.60 (moderate). Variables used for analysis were categorical and included herd, BCSG (1, 2, and 3), LS (1 or 2,3 or 4), NEFA $(<0.30 \mathrm{mEq} / \mathrm{L}$ and $\geq 0.30 \mathrm{mEq} / \mathrm{L})$, CEASE $(1,2$, and $\geq 3)$, CSEX [female(s) and at least 1 male], twins, stillbirth (live calf or calves and at least 1 dead calf), $\mathrm{PDCC}(<272$ and $\geq 272)$, and parity (lactation 1 , lactation 2 , and lactation $\geq 3$ ). Cows with prepartum NEFA values were only included if blood was obtained between 14 and $3 \mathrm{~d}$ before calving and if the hemolytic index was $<300$ in the sample (Stokol and Nydam, 2006). Prepartum blood NEFA concentration was categorized based on studies showing the negative effects of prepartum NEFA $\geq 0.30 \mathrm{mEq} / \mathrm{L}$ on postpartum outcomes (Cameron et al., 1998; Ospina et al., 2010b). The continuous variable PDCC was categorized into early parturition (less than 1 standard deviation below the mean) or normal to prolonged gestation (equal to or greater than 1 standard deviation above the mean).
Not all data were available for all eligible cows, and only cows with complete data were included in the analyses.

Descriptive statistics (chi-squared tests and ANOVA) were generated with PROC FREQ and PROC GLM of SAS (SAS Institute Inc., Cary, NC). The assumptions of normality and homoscedasticity were tested and upheld for BHBA concentration at first positive test for all risk factors before performing ANOVA. Correlation between variables was determined using PROC CORR of SAS, with variables considered to be associated if their correlation coefficient was $\geq 0.3$; no variables met this criteria.

The prediction models were produced using fixed effects multivariable Poisson regression with the PROC GENMOD of SAS (Frome and Checkoway, 1985; Spiegelman and Hertzmark, 2005; Ospina et al., 2012), with an adjustment for overdispersion. All putative risk factors were explored for their univariate association with the outcome of interest using a chi-squared test. Any variable with $P<0.20$ was offered to a multivariable model. Multivariable models were then formed manually via backward stepwise elimination if $P>0.05$. Any remaining variables were offered to the model in pairwise interactions if biologically important; the interactions were then removed manually via backward stepwise elimination if $P>0.05$. Predictive concordance of the final model and actual outcomes were calculated to assess model fit (Steyerberg et al., 2010).

\section{RESULTS}

\section{Descriptive Statistics}

In total, 1,955 cows began the study during their prefreshening period. The 4-herd HYPRKTN model had 1,618 cows eligible for analysis, with data recorded for all variables. The 4 herd HYPRKTN1 model had 1,672 cows eligible for analysis, with data recorded for all variables. The NY HYPRKTN and HYPRKTN1 models had 767 cows eligible for analysis. Of these cows, 544 had data recorded for all variables (233 cows did not have a NEFA value obtained between 14 and 3 d precalving due to variability in actual calving dates). Histograms showing the distributions of precalving LS and BCSG, blood NEFA concentrations (for the NY herds), and PDCC are in Figure 1. Descriptive statistics for the HYPRKTN prediction models for all 4 herds and the 2 NY herds are in Table 1 and Table 2, respectively. Descriptive statistics for the HYPRKTN1 prediction models for all 4 herds and the $2 \mathrm{NY}$ herds are in Table 3 and Table 4, respectively. The incidence of hyperketonemia in cows repeatedly tested from 3 to 
16 DIM was $45.7 \%$; the incidence of hyperketonemia in cows at their first BHBA test at 3 to 5 DIM was $23.0 \%$.

\section{Prediction of Hyperketonemia at Any Time from 3 to 16 DIM}

All 4 Herds. The final model for prediction of hyperketonemia at any time from 3 to 16 DIM was as follows:

$$
\begin{gathered}
\log _{\mathrm{e}}(\text { probability of HYPRKTN })=\mathrm{BCSG} \\
+ \text { parity }+ \text { herd }+ \text { parity } \times \text { herd }+\varepsilon
\end{gathered}
$$

where $\varepsilon$ is a residual error term. Estimated Poisson regression coefficients and risk ratios for the variables included in the model are in Table 5. A $64 \%$ predictive concordance was found with the observed results using this model.

NY Herds. The final model for prediction of hyperketonemia at any time from 3 to 16 DIM was as follows:

$$
\begin{gathered}
\log _{\mathrm{e}}(\text { probability of HYPRKTN })=\text { NEFA } \\
+ \text { CSEX }+ \text { parity }+ \text { herd }+\varepsilon
\end{gathered}
$$

Estimated Poisson regression coefficients and risk ratios for the variables included in the model are in Table 6. No interactions were found between variables. A $69 \%$ predictive concordance was found with the observed results using this model.

\section{Prediction of Hyperketonemia at First BHBA Test}

All 4 Herds. The final model for prediction of hyperketonemia at first test $(3,4$, or 5 DIM) was as follows:

$$
\begin{gathered}
\log _{\mathrm{e}}(\text { probability of HYPRKTN1 })=\text { BCSG } \\
+ \text { CSEX }+ \text { parity }+ \text { herd }+ \text { parity } \times \text { BCSG }+\varepsilon .
\end{gathered}
$$

Estimated Poisson regression coefficients and risk ratios for the variables included in the model are in Table 7. A $78 \%$ predictive concordance was found with the observed results using this model.

NY Herds. The final model for prediction of hyperketonemia at first test $(3,4$, or 5 DIM) was as follows:

$$
\begin{gathered}
\log _{\mathrm{e}}(\text { probability of HYPRKTN1 })=\text { NEFA } \\
+ \text { CSEX }+ \text { CEASE }+ \text { stillbirth }+ \text { parity }+\varepsilon
\end{gathered}
$$

Estimated Poisson regression coefficients and risk ratios for the variables included in the model are in Table 8 .
No interactions were found between variables. An $87 \%$ predictive concordance was found with the observed results using this model.

\section{DISCUSSION}

The reported models were developed to determine important dry and calving period risk factors of (1) a cow developing hyperketonemia at any time between 3 and 16 DIM and (2) a cow having hyperketonemia at her first BHBA test. The results suggested that, in addition to variations in incidence of hyperketonemia between herds, advanced parity may be one of the biggest predictors of hyperketonemia development in early lactation. Moreover, increased BCS precalving, increased precalving blood NEFA concentration, and variables related to the calving process may help to identify at risk animals before hyperketonemia develops.

The important predictors in the model determining the probability of hyperketonemia development at any time between 3 and 16 DIM in all 4 herds included the variables BCSG, parity, and herd. A parity by herd interaction was also present, which precludes interpretation of the parity and herd variables individually. The model determined that cows in BCSG 1 and 2 were less likely to develop hyperketonemia than cows in BCSG 3 ; thus, an increased risk of hyperketonemia development existed in overweight cows with a BCS greater than the median score of cows in the herd. These results are in agreement with Gillund et al. (2001) who found that cows with a BCS of $\geq 3.5$ at calving were associated with increased odds of hyperketonemia in early lactation. Multiple studies have reported on the association between cows overfed during the dry-off period and a greater negative energy balance during their subsequent lactation (Contreras et al., 2004; Dann et al., 2006; Janovick et al., 2011). In addition, Hayirli et al. (2002) found that DMI in the final 3 wk of gestation decreased linearly as BCS increased. From these studies, it follows that cows with an increased BCS at calving have an increased risk of periparturient diseases associated with a greater negative energy balance such as hyperketonemia.

The presence of a parity by herd interaction shows that the risk of hyperketonemia development for each parity group varied depending from which herd they originated. For all herds except farm B, cows in parity 1 and parity 2 were less likely to develop hyperketonemia than cows in parity $\geq 3$. Specifically, cows in parity $\geq 3$ were $2.0(95 \% \mathrm{CI}=1.5$ to 2.6$)$ times more likely on farm A, 1.7 (95\% CI = 1.2 to 2.4 ) times more likely on farm C, and 1.4 (95\% CI $=1.2$ to 1.7) times more likely on farm $\mathrm{D}$ to develop hyperketonemia than cows in parity 1 in each herd, respectively. Cows on farm B had the 
(a)

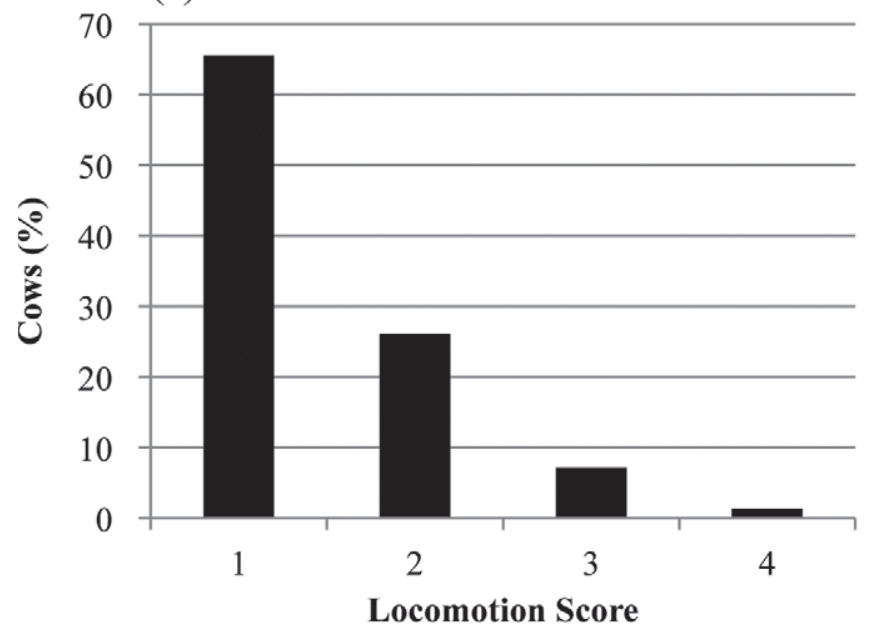

(b)

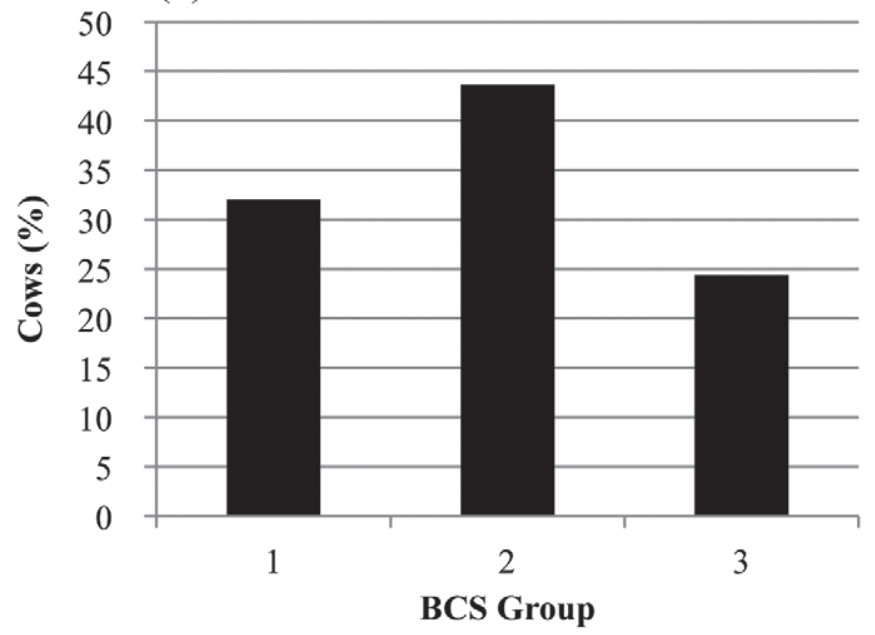

(c)

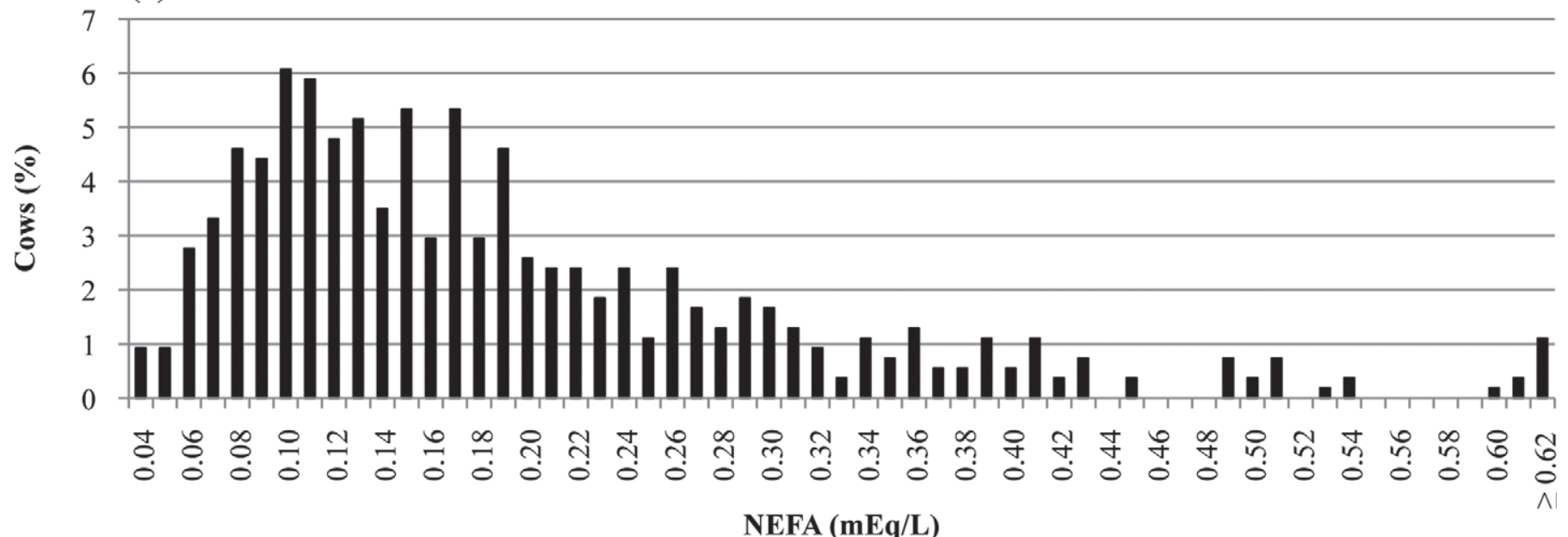

(d)

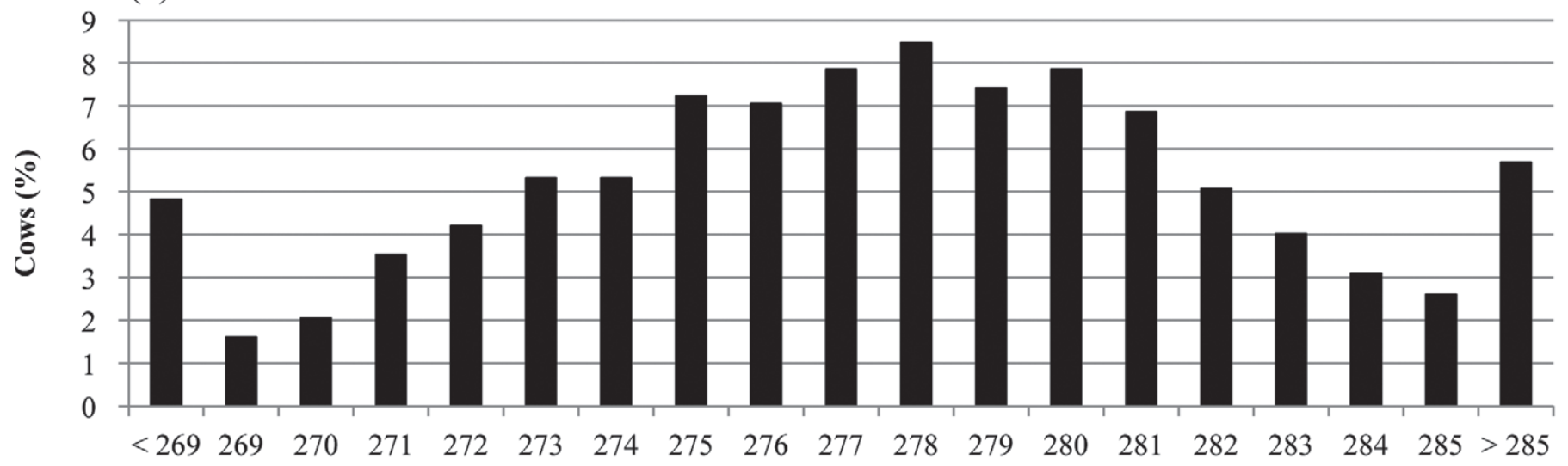

Previous Days Carried Calf

Figure 1. Histograms showing data for 1,618 Holstein cows undergoing repeated testing for hyperketonemia from 3 to 16 DIM on (a) precalving locomotion score, (b) precalving BCS group, (c) precalving blood NEFA concentrations (544 cows), and (d) previous days carried calf. 
Table 1. Descriptive statistics and chi-squared analysis of 1,618 Holstein cows from 4 herds undergoing repeated testing for hyperketonemia from 3 to $16 \mathrm{DIM}^{1}$

\begin{tabular}{|c|c|c|c|}
\hline Variable & $\begin{array}{l}\text { Hyperketonemic } \\
{[\text { no. (\%)] }}\end{array}$ & $\begin{array}{c}\text { Nonhyperketonemic } \\
{[\text { no. }(\%)]}\end{array}$ & $P$-value ${ }^{2}$ \\
\hline \multicolumn{4}{|l|}{ Herd } \\
\hline Farm A & 143 (42.7) & $192(57.3)$ & \multirow[t]{4}{*}{$<0.001$} \\
\hline Farm B & $95(27.1)$ & $256(72.9)$ & \\
\hline Farm C & $120(43.5)$ & $156(56.5)$ & \\
\hline Farm D & $381(58.1)$ & $275(41.9)$ & \\
\hline \multicolumn{4}{|l|}{ BCSG } \\
\hline 1 & $215(41.5)$ & 303 (58.5) & \multirow[t]{3}{*}{$<0.001$} \\
\hline 2 & $293(41.5)$ & $413(58.5)$ & \\
\hline 3 & $231(58.6)$ & $163(41.4)$ & \\
\hline \multicolumn{4}{|l|}{ LS } \\
\hline 1 or 2 & $667(45.0)$ & $815(55.0)$ & \multirow[t]{2}{*}{0.08} \\
\hline 3 or 4 & $72(52.9)$ & $64(47.1)$ & \\
\hline \multicolumn{4}{|l|}{ CEASE } \\
\hline 1 & $596(46.1)$ & $697(53.9)$ & \multirow[t]{3}{*}{0.75} \\
\hline 2 & $98(43.4)$ & $128(56.6)$ & \\
\hline$\geq 3$ & $45(45.5)$ & $54(54.5)$ & \\
\hline \multicolumn{4}{|l|}{ CSEX } \\
\hline Female & $347(44.4)$ & $435(55.6)$ & \multirow[t]{2}{*}{0.31} \\
\hline Male & $392(46.9)$ & $444(53.1)$ & \\
\hline \multicolumn{4}{|l|}{ Twins } \\
\hline 0 & $703(45.7)$ & $835(54.3)$ & \multirow[t]{2}{*}{0.90} \\
\hline 1 & $36(45.0)$ & $44(55.0)$ & \\
\hline \multicolumn{4}{|l|}{ Stillbirth } \\
\hline 0 & $702(45.8)$ & $832(54.2)$ & \multirow[t]{2}{*}{0.76} \\
\hline 1 & $37(44.0)$ & $47(56.0)$ & \\
\hline \multicolumn{4}{|l|}{ PDCC } \\
\hline$<272$ & $96(36.6)$ & $166(63.4)$ & \multirow[t]{2}{*}{0.001} \\
\hline$\geq 272$ & $643(47.4)$ & $713(52.6)$ & \\
\hline \multicolumn{4}{|l|}{ Parity } \\
\hline 1 & $206(37.4)$ & $345(62.6)$ & \multirow[t]{3}{*}{$<0.001$} \\
\hline 2 & $182(37.4)$ & $305(62.6)$ & \\
\hline$\geq 3$ & $351(60.5)$ & $229(39.5)$ & \\
\hline
\end{tabular}

${ }^{1}$ Cows were categorized as hyperketonemic if at any time between 3 and 16 DIM their blood BHBA concentration was $\geq 1.2 \mathrm{mmol} / \mathrm{L}$. Analyzed variables included herd, BCS group (BCSG), locomotion score (LS), calving ease (CEASE), calf sex (CSEX: female or females only, at least 1 male), twins, stillbirth (at least 1 dead calf), previous days carried calf (PDCC), and parity.

${ }^{2} P$-value reported for $\chi^{2}$ statistic.

same risk of hyperketonemia development no matter their parity. This may be due to increased monitoring of older cows or the fact that farm B had the lowest incidence of hyperketonemia among the 4 farms at 27.1 versus $42.6,43.5$, and $58.1 \%$ on farms $\mathrm{A}, \mathrm{C}$, and $\mathrm{D}$, respectively. From these data, it can be suggested that older cows (parity $\geq 3$ ) are at a higher risk of developing hyperketonemia than younger cows. These results are in agreement with many authors who have reported an increase in the prevalence or odds of hyperketonemia in early lactation with increasing parity (Kauppinen, 1983; Gröhn et al., 1989; Duffield et al., 1997).

For the model determining the probability of hyperketonemia development at any time between 3 and 16 DIM in the NY herds, the important predictor variables were precalving NEFA, CSEX, parity, and herd. It is well known that herd management factors are important predictors of hyperketonemia development in cows, and it is therefore likely that a cow's risk of hyperketonemia may be greater solely due to the fact that she resides in a certain herd. For example, cows in this study from farm B were 0.7 times as likely to develop hyperketonemia as cows from farm A. Similar to the model with data from all 4 herds, cows in parity 1 and 2 were less likely to develop hyperketonemia than cows in parity $\geq 3$. Additionally, cows that gave birth to male calves were 1.4 times more likely to develop hyperketonemia than cows birthing female calves. Although the larger size of male calves has been associated with increased calving difficulty and stillbirth (Correa et al., 1993; Johanson and Berger, 2003; Bicalho et al., 2007), CEASE and stillbirth were not important predictors of hyperketonemia development in these studies. Male calves may require more energy in late gestation due to their larger size and this increased energy requirement may result in a larger negative energy balance in early lactation, leading to an increased risk of hyperketonemia development. However, CSEX was not an 
Table 2. Descriptive statistics and chi-squared analysis of 544 Holstein cows from 2 New York herds undergoing repeated testing for hyperketonemia from 3 to $16 \mathrm{DIM}^{1}$

\begin{tabular}{|c|c|c|c|}
\hline Variable & $\begin{array}{l}\text { Hyperketonemic } \\
{[\text { no. }(\%)]}\end{array}$ & $\begin{array}{c}\text { Nonhyperketonemic } \\
{[\text { no. }(\%)]}\end{array}$ & $P$-value ${ }^{2}$ \\
\hline \multicolumn{4}{|l|}{ Herd } \\
\hline Farm A & $105(41.0)$ & $151(59.0)$ & \multirow[t]{2}{*}{$<0.001$} \\
\hline Farm B & $79(27.4)$ & $209(72.6)$ & \\
\hline \multicolumn{4}{|l|}{ BCSG } \\
\hline 1 & $75(34.6)$ & $142(65.4)$ & \multirow[t]{3}{*}{0.91} \\
\hline 2 & $93(33.7)$ & $183(66.3)$ & \\
\hline 3 & $16(31.4)$ & $35(68.6)$ & \\
\hline \multicolumn{4}{|l|}{ LS } \\
\hline 1 or 2 & $173(34.2)$ & $333(65.8)$ & \multirow[t]{2}{*}{0.51} \\
\hline 3 or 4 & $11(29.0)$ & $27(71.0)$ & \\
\hline \multicolumn{4}{|l|}{ NEFA } \\
\hline$<0.30 \mathrm{mEq} / \mathrm{L}$ & $142(31.3)$ & $311(68.7)$ & \multirow[t]{2}{*}{0.006} \\
\hline$\geq 0.30 \mathrm{mEq} / \mathrm{L}$ & $42(46.1)$ & $49(53.9)$ & \\
\hline \multicolumn{4}{|l|}{ CEASE } \\
\hline 1 & $143(33.4)$ & $285(66.6)$ & \multirow[t]{3}{*}{0.79} \\
\hline 2 & $31(36.9)$ & $53(63.1)$ & \\
\hline$\geq 3$ & $10(31.2)$ & $22(68.8)$ & \\
\hline \multicolumn{4}{|l|}{ CSEX } \\
\hline Female & $83(29.9)$ & $195(70.1)$ & \multirow[t]{2}{*}{0.05} \\
\hline Male & $101(38.0)$ & $165(62.0)$ & \\
\hline \multicolumn{4}{|l|}{ Twins } \\
\hline 0 & $178(34.2)$ & $343(65.8)$ & \multirow[t]{2}{*}{0.42} \\
\hline 1 & $6(26.1)$ & $17(73.9)$ & \\
\hline \multicolumn{4}{|l|}{ Stillbirth } \\
\hline 0 & $169(33.2)$ & $340(66.8)$ & \multirow[t]{2}{*}{0.24} \\
\hline 1 & $15(42.9)$ & $20(57.1)$ & \\
\hline \multicolumn{4}{|l|}{ PDCC } \\
\hline$<272$ & $11(22.4)$ & $38(77.6)$ & \multirow[t]{2}{*}{0.08} \\
\hline$\geq 272$ & $173(35.0)$ & $322(65.0)$ & \\
\hline \multicolumn{4}{|l|}{ Parity } \\
\hline 1 & $64(30.3)$ & 147 (69.7) & \multirow[t]{3}{*}{$<0.001$} \\
\hline 2 & $31(19.6)$ & $127(80.4)$ & \\
\hline$\geq 3$ & $89(50.9)$ & $86(49.1)$ & \\
\hline
\end{tabular}

important predictor of hyperketonemia in the model with data from all 4 herds suggesting that herd and parity may be more important variables to monitor.

Cows from NY with precalving blood NEFA concentrations $\geq 0.30 \mathrm{mEq} / \mathrm{L}$ were 1.3 times more likely to develop hyperketonemia between 3 and 16 DIM than cows with NEFA concentrations $<0.30 \mathrm{mEq} / \mathrm{L}$. As BCSG was not an important predictor of hyperketonemia in this model, it follows that precalving blood NEFA concentrations were a better indicator of hyperketonemia development between 3 and 16 DIM than precalving body condition. Although precalving blood NEFA concentrations are a less subjective measure than BCS, the cost of labor to collect blood and process samples as well as the expense to run the test in a diagnostic laboratory, currently $\$ 11.00$ per sample at the New York State Animal Health Diagnostic Center (http://ahdc.vet.cornell.edu/test), makes collection of precalving NEFA data less attractive. Based on the results of the prediction model using all 4 herds, if the cost of collection and processing prevent availability of precalving NEFA data, a simpler, though less predictive, measurement would include precalving BCS, assuming it is consistently scored on a farm by the same individual.

The important variables from the model using data from all 4 herds to predict hyperketonemia at first BHBA test were similar to those discussed above for predicting hyperketonemia at any time between 3 and 16 DIM, specifically CSEX, herd, and a parity by BCSG interaction. Additionally, cows birthing male calves were 1.2 times more likely to have hyperketonemia at first BHBA test than cows that delivered females. The parity by BCSG interaction showed no increase in risk of hyperketonemia for parity 1 cows, regardless of their BCSG. However, parity 2 cows in BCSG 3 and parity 3 cows in BCSG 2 or 3 were approximately twice as likely to have hyperketonemia at first BHBA test than parity 1 cows in BCSG 1 . These results suggest that older 
Table 3. Descriptive statistics, chi-squared analyses, and ANOVA for 1,672 Holstein cows with a blood BHBA concentration (mmol/L) recorded at first BHBA test (between 3 and 5 DIM) $)^{1}$

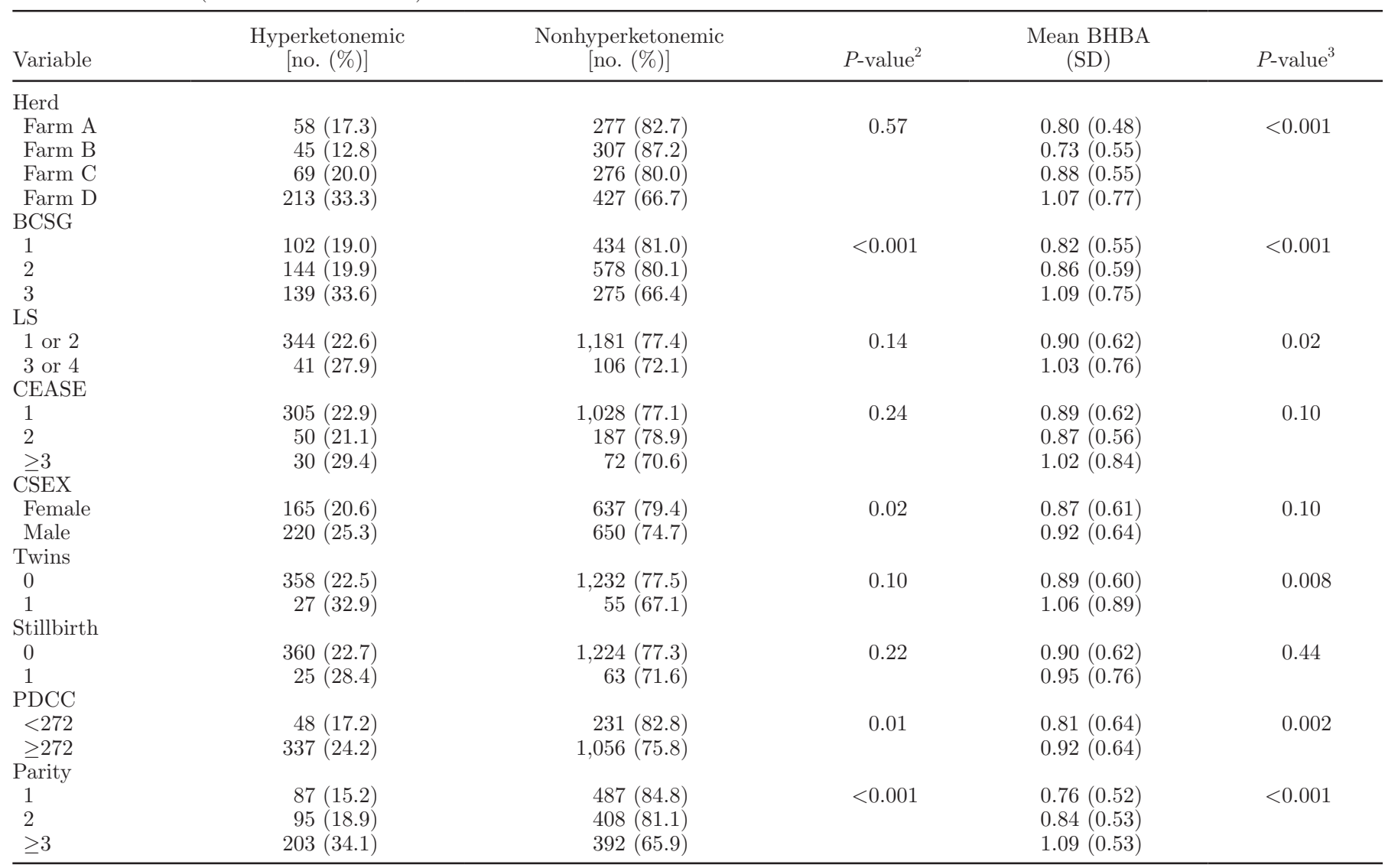

${ }^{1}$ Cows were categorized as hyperketonemic if their BHBA concentration was $\geq 1.2 \mathrm{mmol} / \mathrm{L}$. Analyzed variables included herd, BCS group (BCSG), locomotion score (LS), calving ease (CEASE), calf sex [CSEX: female(s), at least 1 male], twins, stillbirth (at least 1 dead calf), previous days carried calf (PDCC), and parity.

${ }^{2} P$-value reported for $\chi^{2}$ statistic.

${ }^{3} P$-value reported for $F$-test statistic.

cows with greater body condition are at a higher risk of early lactation hyperketonemia development, and that parity 1 cows are somehow able to compensate for the increased risk associated with a greater body condition. It can be postulated that this compensation may be due to the fact that parity 1 cows make less milk than older animals and, thus, less energy is needed for milk production, decreasing the magnitude of negative energy balance in these young cows.

For the model predicting hyperketonemia development at first BHBA test using only data from the NY herds, the important predictor variables were precalving NEFA, CSEX, CEASE, stillbirth, and parity. As with the other models, cows birthing male calves were more likely to develop hyperketonemia than cows birthing females, and parity 3 cows had a higher risk of hyperketonemia development than parity 1 or 2 cows. Similarly to the NY model predicting hyperketonemia at any time between 3 and 16 DIM, cows with precalv- ing NEFA $\geq 0.30 \mathrm{mEq} / \mathrm{L}$ were more likely to develop hyperketonemia at first BHBA test than cows with precalving NEFA $<0.30 \mathrm{mEq} / \mathrm{L}$. However, the magnitude of the NEFA effect was greater for the model predicting hyperketonemia at first BHBA test, with high NEFA cows almost twice as likely to have hyperketonemia at first BHBA test compared with low NEFA cows. In addition to the aforementioned variables, cows with a CEASE $\geq 3$ and cows delivering at least 1 stillborn calf were 2.6 and 2.2 times more likely to develop hyperketonemia than cows with a CEASE of 1 or cows birthing live calves, respectively. It is likely that cows with difficult births have a decreased DMI in early lactation, and it is possible that this decrease in intake has a negative effect on energy balance in early lactation, which increases the risk of hyperketonemia.

The models developed to predict hyperketonemia at first BHBA test had a higher predictive concordance at $78 \%$ (all 4 herds) and 87\% (NY herds) than the models 
Table 4. Descriptive statistics, chi-squared analyses, and ANOVA of 544 Holstein cows in New York State with a blood BHBA concentration $(\mathrm{mmol} / \mathrm{L})$ recorded between 3 and $5 \mathrm{DIM}^{1}$

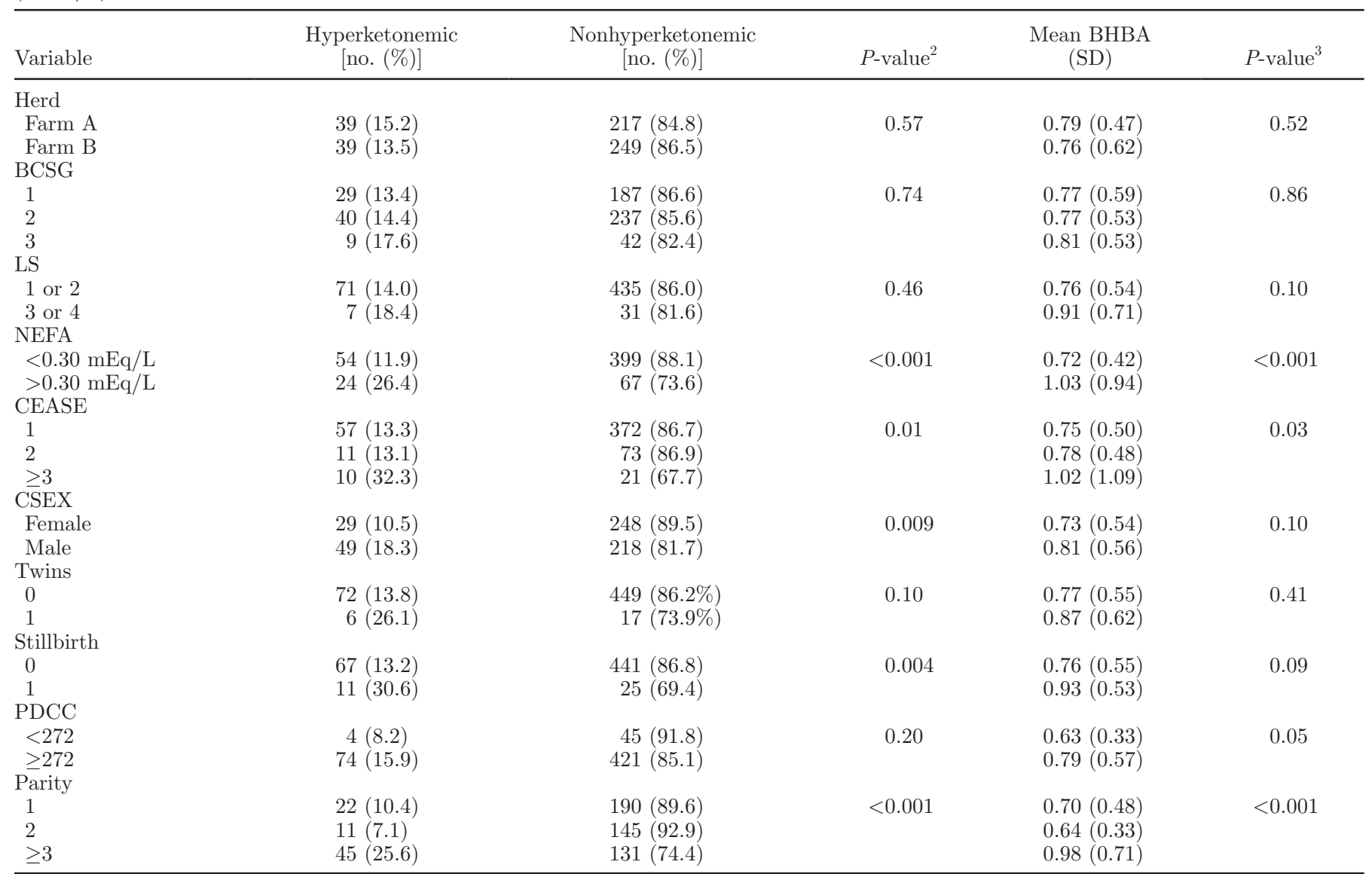

${ }^{1}$ Cows were categorized as hyperketonemic if their BHBA concentration was $\geq 1.2 \mathrm{mmol} / \mathrm{L}$. Analyzed variables included herd, BCS group (BCSG), locomotion score (LS), NEFA, calving ease (CEASE), calf sex [CSEX: female(s), at least 1 male], twins, stillbirth (at least 1 dead calf), previous days carried calf (PDCC), and parity.

${ }^{2} P$-value reported for $\chi^{2}$ statistic.

${ }^{3} P$-value reported for $F$-test statistic.

predicting hyperketonemia at any time between 3 and 16 DIM at 64\% (all 4 herds) and 69\% (NY herds). Predictive concordance is a measure of model accuracy. For example, the NY model for hyperketonemia at first BHBA test correctly predicted $87 \%$ of cows that developed hyperketonemia during that time frame in the sampled NY herds. The models predicting hyperketonemia at first BHBA test may be more accurate than those predicting hyperketonemia at any time between 3 and 16 DIM because the effect of dry and calving period predictors may wane as time progresses. However, as $75 \%$ of cows hyperketonemia positive cows in this study first tested positive between 3 and 7 DIM (McArt et al., 2012), it is reasonable to suggest that the early predictor models may be of greater benefit than the models predicting hyperketonemia at any time between 3 and 16 DIM.
A cow's risk for developing hyperketonemia depends on in which herd she resides, with cows in herds with a high incidence of early lactation hyperketonemia at a greater risk of developing hyperketonemia themselves. Within herds, the best predictors of early lactation hyperketonemia development in this study included parity, precalving NEFA, precalving BCS, and birth of a male calf. From these results, it can be suggested that increased monitoring and testing of fresh cows be focused on parity $\geq 3$ cows, cows entering lactation with a blood NEFA concentration $\geq 0.3 \mathrm{mEq} / \mathrm{L}$ or BCS greater than the median of the herd, and cows that had difficulty giving birth or birthed male calves. However, these results do not suggest that cows in parity 1 or thin cows do not develop hyperketonemia in early lactation, only that they are at a decreased risk of developing the disease. 
Table 5. Maximum likelihood estimates of Poisson regression coefficients $(\beta)$, standard errors, risk ratios (RR), and 95\% confidence intervals for model variables used in the prediction of hyperketonemia (blood BHBA concentration $\geq 1.2 \mathrm{mmol} / \mathrm{L}$ ) at any time from 3 to 16 DIM in 1,618 Holstein cows from all 4 herds undergoing repeated monitoring for hyperketonemia ${ }^{1}$

\begin{tabular}{|c|c|c|c|c|}
\hline Parameter & $\beta$ & SE & $P$-value ${ }^{2}$ & $\mathrm{RR}(95 \% \mathrm{CI})$ \\
\hline Intercept & -0.85 & 0.10 & $<0.001$ & - \\
\hline \multicolumn{5}{|l|}{ BCSG } \\
\hline 1 & $-^{3}$ & - & 0.003 & - \\
\hline 2 & 0.05 & 0.07 & & $1.1(0.9$ to 1.2$)$ \\
\hline 3 & 0.25 & 0.08 & & $1.2(1.1$ to 1.5$)$ \\
\hline \multicolumn{5}{|l|}{ Parity $\times$ herd } \\
\hline 1, Farm A & $ـ^{3}$ & - & 0.001 & - \\
\hline 1, Farm B & -0.20 & 0.17 & & $0.8(0.6$ to 1.1$)$ \\
\hline 1, Farm C & -0.03 & 0.18 & & $1.0(0.7$ to 1.4$)$ \\
\hline 1, Farm D & 0.36 & 0.14 & & $1.4(1.1$ to 2.0$)$ \\
\hline 2, Farm A & 0.15 & 0.18 & & $1.2(0.8$ to 1.7$)$ \\
\hline 2, Farm B & -0.88 & 0.22 & & $0.4(0.3$ to 0.6$)$ \\
\hline 2, Farm $\mathrm{C}$ & 0.25 & 0.16 & & 1.3 (0.9 to 1.8$)$ \\
\hline 2, Farm D & 0.47 & 0.14 & & $1.6(1.2$ to 2.1$)$ \\
\hline$\geq 3$, Farm A & 0.69 & 0.15 & & 2.0 (1.5 to 2.6$)$ \\
\hline$\geq 3$, Farm B & 0.28 & 0.16 & & $1.3(1.0$ to 1.8$)$ \\
\hline$\geq 3$, Farm $\mathrm{C}$ & 0.50 & 0.16 & & $1.6(1.2$ to 2.3$)$ \\
\hline$\geq 3$, Farm D & 0.72 & 0.13 & & $2.0(1.6$ to 2.7$)$ \\
\hline
\end{tabular}

${ }^{1}$ Variables retained in the final model included parity, BCS group (BCSG), and herd. As an interaction was found between parity and herd, the reported variables only include BSCG and the parity $\times$ herd interaction.

${ }^{2} P$-value reported for coefficient estimate of entire variable.

${ }^{3}$ Reference group.

\section{CONCLUSIONS}

Advanced parity was a major predictor of hyperketonemia development in early lactation after herd-level hyperketonemia incidence was taken into account. Additionally, increased precalving BCS, increased precalving blood NEFA concentration, and variables related to a more difficult calving process (high CEASE score or stillbirth) may help identify at risk animals before hyperketonemia develops.

\section{ACKNOWLEDGMENTS}

This study was funded in part by the US Department of Agriculture-National Research Initiative (USDANRI no. 2008-55204-19393) and Boehringer Ingelheim

Table 6. Maximum likelihood estimates of Poisson regression coefficients $(\beta)$, standard errors, risk ratios $(\mathrm{RR}$ ), and $95 \%$ confidence intervals for model variables used in the prediction of hyperketonemia (blood BHBA concentration $\geq 1.2 \mathrm{mmol} / \mathrm{L}$ ) at any time from 3 to 16 DIM in 544 Holstein cows from New York State undergoing repeated monitoring for hyperketonemia ${ }^{1}$

\begin{tabular}{|c|c|c|c|c|}
\hline Parameter & $\beta$ & $\mathrm{SE}$ & $P$-value ${ }^{2}$ & RR $(95 \%$ CI $)$ \\
\hline Intercept & -1.26 & 0.14 & $<0.001$ & - \\
\hline \multicolumn{5}{|l|}{ NEFA } \\
\hline$<0.30 \mathrm{mEq} / \mathrm{L}$ & -3 & - & \multirow[t]{2}{*}{0.05} & - \\
\hline$\geq 0.30 \mathrm{mEq} / \mathrm{L}$ & 0.28 & 0.14 & & 1.3 (1.0 to 1.8$)$ \\
\hline \multicolumn{5}{|l|}{$\overline{C S E X}$} \\
\hline Female & -3 & - & \multirow[t]{2}{*}{0.01} & - \\
\hline Male & 0.30 & 0.12 & & $1.4(1.1$ to 1.7$)$ \\
\hline \multicolumn{5}{|l|}{ Parity } \\
\hline 1 & $ـ^{3}$ & - & \multirow[t]{3}{*}{$<0.001$} & - \\
\hline 2 & -0.29 & 0.18 & & $0.7(0.5$ to 1.0$)$ \\
\hline$\geq 3$ & 0.60 & 0.13 & & $1.7(1.3$ to 2.2$)$ \\
\hline \multicolumn{5}{|l|}{ Herd } \\
\hline Farm A & $-^{3}$ & - & \multirow[t]{2}{*}{0.005} & - \\
\hline Farm B & -0.34 & 0.12 & & 0.7 (0.6 to 0.9$)$ \\
\hline
\end{tabular}

${ }^{1}$ Variables retained in the final model included NEFA, calf sex [CSEX: female(s), at least 1 male], parity, and herd.

${ }^{2} P$-value reported for coefficient estimate of entire variable.

${ }^{3}$ Reference group. 
Table 7. Maximum likelihood estimates of Poisson regression coefficients ( $\beta$ ), standard errors, adjusted risk ratios (RR), and 95\% confidence intervals for model variables used in the prediction of hyperketonemia (blood BHBA concentration $\geq 1.2 \mathrm{mmol} / \mathrm{L})$ on the first test after parturition $(3,4$, or 5 DIM) in 1,672 Holstein cows from all 4 herds $^{1}$

\begin{tabular}{|c|c|c|c|c|}
\hline Parameter & $\beta$ & $\mathrm{SE}$ & $P$-value ${ }^{2}$ & $\mathrm{RR}(95 \% \mathrm{CI})$ \\
\hline Intercept & -4.48 & 0.58 & $<0.001$ & - \\
\hline \multicolumn{5}{|l|}{ CSEX } \\
\hline Female & $-^{3}$ & - & \multirow[t]{2}{*}{0.03} & - \\
\hline Male & 0.20 & 0.09 & & $1.2(1.0$ to 1.5$)$ \\
\hline \multicolumn{5}{|l|}{ Herd } \\
\hline Farm A & $-^{3}$ & - & \multirow[t]{4}{*}{$<0.001$} & - \\
\hline Farm B & -0.32 & 0.18 & & $0.7(0.5$ to 1.0$)$ \\
\hline Farm C & -0.01 & 0.16 & & $1.0(0.7$ to 1.4$)$ \\
\hline Farm D & 0.48 & 0.14 & & $1.6(1.2$ to 2.1$)$ \\
\hline \multicolumn{5}{|c|}{ Parity $\times$ BCSG } \\
\hline $1,{ }^{4} 1^{5}$ & $-^{3}$ & - & \multirow[t]{9}{*}{0.004} & - \\
\hline 1,2 & -0.19 & 0.28 & & 0.8 (0.5 to 1.4$)$ \\
\hline 1,3 & -0.17 & 0.30 & & $0.8(0.5$ to 1.5$)$ \\
\hline 2,1 & -0.24 & 0.29 & & $0.8(0.4$ to 1.4$)$ \\
\hline 2,2 & -0.16 & 0.30 & & $0.9(0.5$ to 1.5$)$ \\
\hline 2,3 & 0.82 & 0.29 & & $2.2(1.3$ to 4.0$)$ \\
\hline$\geq 3,1$ & 0.42 & 0.27 & & 1.5 (0.9 to 2.6$)$ \\
\hline$\geq 3,2$ & 0.58 & 0.27 & & $1.8(1.1$ to 3.0$)$ \\
\hline$\geq 3,3$ & 0.80 & 0.27 & & $2.2(1.3$ to 3.8$)$ \\
\hline
\end{tabular}

${ }^{1}$ Variables retained in the final model included herd, calf sex [CSEX: female(s), at least 1 male], parity, and BCS group (BCSG). As an interaction was found between parity and BCSG, the reported variables include CSEX, herd, and the parity $\times$ BCSG interaction.

${ }^{2} P$-value reported for coefficient estimate for entire variable.

${ }^{3}$ Reference group.

${ }^{4}$ Parity.

${ }^{5}$ BCSG.

Vetmedica Inc. (St. Joseph, MO). The authors thank Judith Alishauskas, Stephanie Brittin, Emily Bold, Mark Fagan, and Caitlin Jeffrey (Cornell University, Niles, Tyler Franks, Catherine Bargren, Diego Calderon, Cristian Vergara, and Loïc Commun (University of Wisconsin, Madison) for their invaluable assistance Ithaca, NY), and Lindley Reilly, Eric Rooker, Angela with data collection, as well as the owners of the col-

Table 8. Maximum likelihood estimates of Poisson regression coefficients ( $\beta$ ), standard errors, adjusted risk ratios (RR), and $95 \%$ confidence intervals for model variables used in the prediction of hyperketonemia (blood BHBA concentration $\geq 1.2 \mathrm{mmol} / \mathrm{L})$ on the first test after parturition $(3,4$, or 5 DIM) in 544 Holstein cows from New York State ${ }^{1}$

\begin{tabular}{|c|c|c|c|c|}
\hline Parameter & $\beta$ & SE & $P$-value ${ }^{2}$ & $\mathrm{RR}(95 \% \mathrm{CI})$ \\
\hline Intercept & -3.06 & 0.28 & $<0.001$ & - \\
\hline \multicolumn{5}{|l|}{ NEFA } \\
\hline$<0.30 \mathrm{mEq} / \mathrm{L}$ & -3 & - & \multirow[t]{2}{*}{0.008} & - \\
\hline$\geq 0.30 \mathrm{mEq} / \mathrm{L}$ & 0.62 & 0.23 & & $1.9(1.2$ to 2.9$)$ \\
\hline \multicolumn{5}{|l|}{ CSEX } \\
\hline Female & -3 & - & \multirow[t]{2}{*}{0.007} & - \\
\hline Male & 0.59 & 0.22 & & $1.8(1.2$ to 2.7$)$ \\
\hline \multicolumn{5}{|l|}{ CEASE } \\
\hline 1 & $-^{3}$ & - & \multirow[t]{3}{*}{0.04} & - \\
\hline 2 & 0.13 & 0.31 & & $1.1(0.6$ to 2.1$)$ \\
\hline$\geq 3$ & 0.95 & 0.33 & & $2.6(1.4$ to 5.0$)$ \\
\hline \multicolumn{5}{|l|}{ Stillbirth } \\
\hline 0 & $-^{3}$ & - & \multirow[t]{2}{*}{0.01} & - \\
\hline 1 & 0.78 & 0.31 & & $2.2(1.2$ to 4.0$)$ \\
\hline \multicolumn{5}{|l|}{ Parity } \\
\hline 1 & $ـ^{3}$ & - & \multirow[t]{3}{*}{$<0.001$} & - \\
\hline 2 & -0.17 & 0.35 & & $0.8(0.4$ to 1.7$)$ \\
\hline$\geq 3$ & 1.11 & 0.26 & & 3.0 (1.8 to 5.0$)$ \\
\hline
\end{tabular}

${ }^{1}$ Variables retained in the final model included NEFA, calf sex [CSEX: female(s), at least 1 male], calving ease (CEASE), stillbirth, and parity.

${ }^{2} P$-value reported for coefficient estimate for entire variable.

${ }^{3}$ Reference group. 
laborating dairies for allowing us access to their facilities and cows on which to conduct this research.

\section{REFERENCES}

Baird, G. D. 1982. Primary ketosis in the high-producing dairy cow: Clinical and subclinical disorders, treatment, prevention, and outlook. J. Dairy Sci. 65:1-10.

Bauman, D. E., and W. B. Currie. 1980. Partitioning of nutrients during pregnancy and lactation: A review of mechanisms involving homeostasis and homeorhesis. J. Dairy Sci. 63:1514-1529.

Bicalho, R. C., K. N. Galvão, S. H. Cheong, R. O. Gilbert, L. D. Warnick, and C. L. Guard. 2007. Effect of stillbirths on dam survival and reproduction performance in Holstein dairy cows. J. Dairy Sci. 90:2797-2803.

Cameron, R. E. B, P. B. Dyk, T. H. Herdt, J. B. Kaneene, R. Miller, H. F. Bucholtz, J. S. Liesman, M. J. Vandehaar, and R. S. Emery. 1998. Dry cow diet, management, and energy balance as risk factors for displaced abomasum in high producing dairy herds. J. Dairy Sci. 81:132-139.

Contreras, L. L., C. M. Ryan, and T. R. Overton. 2004. Effects of dry cow grouping strategy and prepartum body condition score on performance and health of transition dairy cows. J. Dairy Sci. $87: 517-523$.

Correa, M. T., H. Erb, and J. Scarlett. 1993. Path analysis for seven postpartum disorders of Holstein cows. J. Dairy Sci. 76:13051312.

Dann, H. M., N. B. Litherland, J. P. Underwood, M. Bionaz, D. D'Angelo, J. W. McFadden, and J. K. Drackley. 2006. Diets during far-off and close-up dry periods affect periparturient metabolism and lactation in multiparous cows. J. Dairy Sci. 89:3563-3577.

Dohoo, I. R., and S. W. Martin. 1984. Subclinical ketosis: Prevalence and associations with production and disease. Can. J. Comp. Med. 48:1-5.

Douglas, G. N., T. R. Overton, H. G. Bateman II, H. M. Dann, and J. K. Drackley. 2006. Prepartal plan of nutrition, regardless of dietary energy source, affects periparturient metabolism and dry matter intake in Holstein cows. J. Dairy Sci. 89:2141-2157.

Duffield, T. F., D. F. Kelton, K. E. Leslie, K. D. Lissemore, and J. H. Lumsden. 1997. Use of test day milk fat and milk protein to detect subclinical ketosis in dairy cattle in Ontario. Can. Vet. J. 38:713-718.

Duffield, T. F., K. D. Lissemore, B. W. McBride, and K. E. Leslie. 2009. Impact of hyperketonemia in early lactation dairy cows on health and production. J. Dairy Sci. 92:571-580.

Ferguson, J. D., D. T. Galligan, and N. Thomsen. 1994. Principal descriptors of body condition score in Holstein cows. J. Dairy Sci. 77:2695-2703.

Frome, E. L., and H. Checkoway. 1985. Epidemiologic programs for computers and calculators. Use of Poisson regression models in estimating incidence rates and ratios. Am. J. Epidemiol. 121:309 323.

Geishauser, T., K. Leslie, D. Kelton, and T. F. Duffield. 2001. Monitoring for subclinical ketosis in dairy herds. Compend. Contin. Educ. Pract. Vet. 23:S65-S71.

Gillund, P., O. Reksen, Y. T. Grohn, and K. Karlberg. 2001. Body condition related to ketosis and reproductive performance in Norwegian dairy cows. J. Dairy Sci. 84:1390-1396.

Gröhn, Y. T., S. W. Eicker, V. Ducrocq, and J. A. Hertl. 1998. Effect of diseases on the culling of Holstein dairy cows in New York State. J. Dairy Sci. 81:966-978.

Gröhn, Y. T., H. N. Erb, C. E. McCulloch, and H. S. Saloniemi. 1989. Epidemiology of metabolic disorders in dairy cattle: Association among host characteristics, disease, and production. J. Dairy Sci. $72: 1876-1885$

Hayirli, A., R. R. Grummer, E. V. Nordheim, and P. M. Crump. 2002. Animal and dietary factors affecting intake during the prefresh transition period in Holsteins. J. Dairy Sci. 85:3430-3443.
Herdt, T. H. 2000. Ruminant adaptation to negative energy balance. Influences on the etiology of ketosis and fatty liver. Vet. Clin. North Am. Food Anim. Pract. 16:215-230.

Iwersen, M., U. Falkenberg, R. Voigtsberger, D. Forderung, and W. Heuwieser. 2009. Evaluation of an electronic cowside test to detect subclinical ketosis in dairy cows. J. Dairy Sci. 92:2618-2624.

Janovick, N. A., Y. R. Boisclair, and J. K. Drackley. 2011. Prepartum dietary energy intake affects metabolism and health during the periparturient period in primiparous and multiparous Holstein cows. J. Dairy Sci. 94:1385-1400

Johanson, J. M., and P. J. Berger. 2003. Birth weight as a predictor of calving ease and perinatal mortality in Holstein cattle. J. Dairy Sci. 86:3745-3755.

Kauppinen, K. 1983. Prevalence of bovine ketosis in relation to number and stage of lactation. Acta Vet. Scand. 24:349-361.

Konkol, K., S. Godden, P. Rapnicki, and M. Overton. 2009. Validation of a rapid cow-side test for the measurement of blood betahydroxybutyrate in fresh cows. Page 190 in Proc. 42nd Annual Conf., Am. Assoc. Bovine Pract., Omaha, NE. VM Publishing Co., Stillwater, OK.

Landis, J. R., and G. G. Koch. 1977. The measurement of observer agreement for categorical data. Biometrics 33:159-174.

LeBlanc, S. J., K. E. Leslie, and T. F. Duffield. 2005. Metabolic predictors of displaced abomasum in dairy cattle. J. Dairy Sci. $88: 159-170$

McArt, J. A. A., D. V. Nydam, and G. R. Oetzel. 2012. Epidemiology of subclinical ketosis in early lactation dairy cattle. J. Dairy Sci. 95:5056-5066.

McArt, J. A. A., D. V. Nydam, P. A. Ospina, and G. R. Oetzel. 2011. A field trial on the effect of propylene glycol on milk yield and resolution of ketosis in fresh cows diagnosed with subclinical ketosis. J. Dairy Sci. 94:6011-6020.

McLaren, C. J., K. D. Lissemore, T. F. Duffield, K. E. Leslie, D. F. Kelton, and B. Grexton. 2006. The relationship between herd level disease incidence and a return over feed index in Ontario dairy herds. Can. Vet. J. 47:767-773.

Nordlund, K. V., N. B. Cook, and G. R. Oetzel. 2004. Investigation strategies for laminitis problem herds. J. Dairy Sci. 87(E. Suppl.):E27-E35.

Ospina, P. A., D. V. Nydam, and T. J. DiCiccio. 2012. Technical note: The risk ratio, an alternative to the odds ratio for estimating the association between multiple risk factors and a dichotomous outcome. J. Dairy Sci. 95:2576-2584. http://dx.doi.org/10.3168/ jds.2011-4515.

Ospina, P. A., D. V. Nydam, T. Stokol, and T. R. Overton. 2010a. Association between the proportion of sampled transition cows with increased nonesterified fatty acids and $\beta$-hydroxybutyrate and disease incidence, pregnancy rate, and milk production at the herd level. J. Dairy Sci. 93:3595-3601.

Ospina, P. A., D. V. Nydam, T. Stokol, and T. R. Overton. 2010b. Associations of elevated nonesterified fatty acids and $\beta$-hydroxybutyrate concentrations with early lactation reproductive performance and milk production in transition dairy cattle in the Northeastern United States. J. Dairy Sci. 93:1596-1603.

Overton, T. R., and M. R. Waldron. 2004. Nutritional management of transition dairy cows: Strategies to optimize metabolic health. J. Dairy Sci. 87(E. Suppl.):E105-E119.

Spiegelman, D., and E. Hertzmark. 2005. Easy SAS calculations for risk or prevalence ratios and differences. Am. J. Epidemiol. 162:199-200

Steyerberg, E. W., A. J. Vickers, N. R. Cook, T. Gerds, M. Gonen, N. Obuchowski, M. J. Pencina, and M. W. Kattan. 2010. Assessing the performance of prediction models: A framework for traditional and novel measures. Epidemiology 21:128-138.

Stokol, T., and D. V. Nydam. 2005. Effect of anticoagulant and storage conditions on bovine nonesterified fatty acid and $\beta$-hydroxybutyrate concentrations in blood. J. Dairy Sci. 88:3139-3144.

Stokol, T., and D. V. Nydam. 2006. Effect of hemolysis on nonesterified fatty acid and $\beta$ - hydroxybutyrate concentrations in bovine blood. J. Vet. Diagn. Invest. 18:466-469. 